Goldsmiths College, em Londres. Desenvolve produtos têxteis para o mercado do vestuário e da decoração e colabora em programas de educação e pós-graduação em artes, têxteis e moda. É pesquisador em artes, cronista, curador e fotógrafo clandestino.

E-mail: ferpen@macbbs.com.br

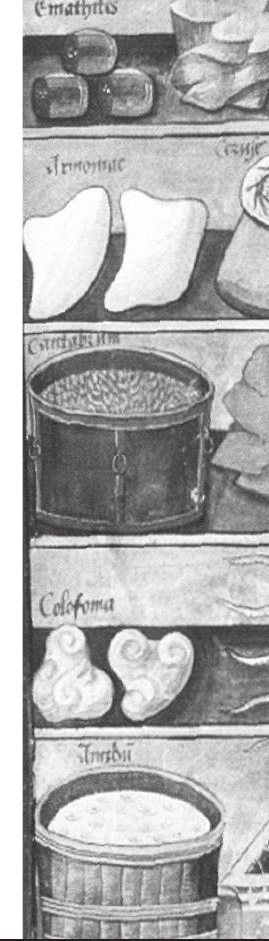

\title{
De tempos em tempos: têxteis
}

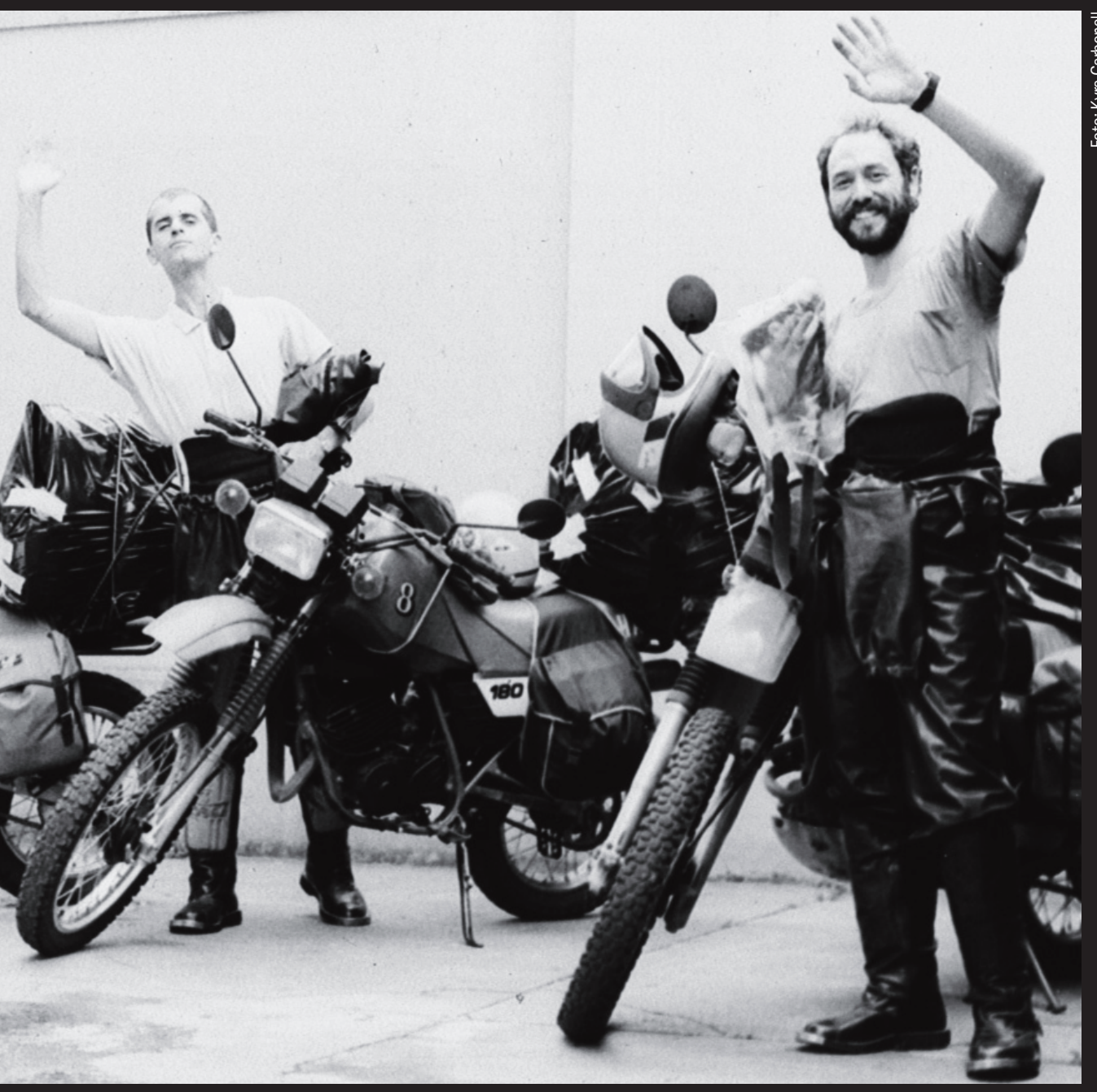

Mario Ramiro e Oscar Bressane, 1987, em partida para sua exploração pelas Minas Gerais em busca de plantas para tinturas, seguindo a rota dos naturalistas Von Spix e Von Martius. 
produção e a distribuição de resultados entre as comunidades locais, aumenta riquezas e não as concentra na mão de poucos.

\section{Tecnologias e impactos}

Sobre tecnologias, a ideia mais empolgante no livro é justamente aquela que, na contramão da exaltação, coloca que dar crédito aos correntes avanços tecnológicos e contar com a tecnologia para oferecer solução a todos os nossos modernos e futuros problemas contêm o efeito insidioso e sutil de reforçar nossa tendência de evitar uma reflexão quanto ao impacto ambiental e social que corroboramos ao "praticarmos" a vida moderna. Enquanto ao sujeito moderno lhe é desenhada uma vida de agilidade, mobilidade, desempenho e eficiência, o livro ilustra decisões malsãs ligadas à compra e, principalmente, à poluente e energeticamente dispendiosa fase de manutenção de roupas e de tecidos (lavagem e reciclagem), e aponta que 0 sujeito obtém melhores resultados quando aplica métodos simples e antigos de cuidados e de lavagem às suas peças, em vez de dirigir-se às cegas para os (sempre) novos (e ferozes) produtos de limpeza com pesquisa, dita, de tecnologia de ponta.

Em relação às fibras, muito vem se fazendo para recompor uma constelação menos agressiva e unidirecionada em relação ao que orgânica ou quimicamente hoje se produz. Das ideias mencionadas, a que, creio, nunca podemos nos distanciar é a de que produzir grandes volumes de um número limitado de fibras é concentrar o impacto em um só setor, tanto da agricultura quanto da manufatura, crescendo o risco ecológico e fazendo do setor um parceiro menos aberto às inevitáveis mudanças globais, não só no que diz respeito a negócios, mas também

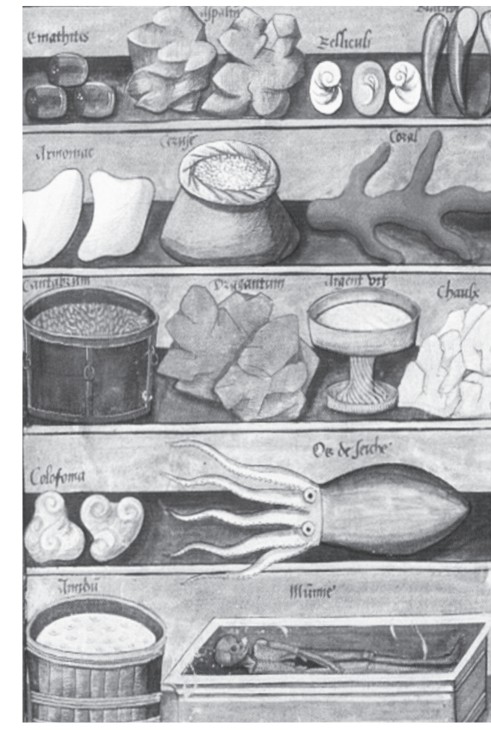

llustração de um manuscrito do século XIV que representa os usos de plantas, produtos minerais e animais para a fabricação de corantes, para a pintura e a tinturação. Fonte: DELAMARE, $\mathrm{F}$ GUINEAU, B. Colour: making and using dyes and pigments. Londres: Thames \& Hudson, 1999, p. 55 no que concerne ao meio ambiente. Para que a variação de plantio, que inclui um olhar mais sensivel às fibras regionais, $\mathrm{e}$ a manufatura de novas fibras aconteçam, é o mercado, ele mesmo, incluindo o consumidor, que deve agir e exigir maior pesquisa e práticas que possibilitem que um maior e mais estável estoque de fibras de menor impacto ambiental estejam disponíveis nos mercados. Enquanto isso, e lidando com tudo que já está em curso na indústria têxtil operante, a indústria conscienciosa cuida em sanar a fase mais poluente da construção de uma superficie têxtil que é o seu acabamento (leia-se tinturação e embelezamentos). De todos os exemplos que Fletcher recolhe, o que mais me tocou foi o de um tecido para decoração de lã e de rami de nome Climatex Lifecycle, desenvolvido pelo moinho suiço Rohner Textil em parceria com a companhia Design Text. Esse tecido, desenhado para responder a um ciclo biodegradável impecável, no qual ele é integralmente compostado ao fim de sua vida útil, foi colorido com tinturas rigorosamente selecionadas por não conterem ou liberarem substâncias cancerígenas, metálicas ou químicas. E, vejam vocês, de uma cartela de 4500 cores que a BASF, soberana indústria mundial de corantes, no momento desse desenvolvimento, punha à disposição para colorir o Climatex Lifecycle, só 16 delas (3\%) foram consideradas adequadas.

E é desses 3\% de cores sobreviventes que brota uma série de perguntas: e ai galera, e então... e aí você que pesquisa, pinta e tinge, você estilista e criador, você moda... a cartela do meio ambiente sofreu um corte "animal" e sobraram 16 cores corretas... é ai Vogue... e aí Dolce \& Gabbana... como é que vai se virar, meu irmão? E nós vamos ser capazes de implodir nosso imaginário cromático, cinematográfico, e, God, deixar de viver sem 0 pink, punks e fluorescentes, sem os tons de elegância franco-italiana que dita a China, que move os coreanos que dominam a popular José Paulino, o Bom Retiro e a compra a granel? Como vamos continuar a estetizar nossos sonhos e nossos projetos têxteis futuros quando eles comprovadamente se mostram 97\% ambientalmente insustentáveis? Como as indústrias vão lucrar a partir desse master-eco-ético-princípio-cromático e evitar usar cores nocivas... e... quando vamos passar a ganhar, todos, com essas novas éticas e mudanças? $\mathrm{E}$, me digam, que tempos são esses? 


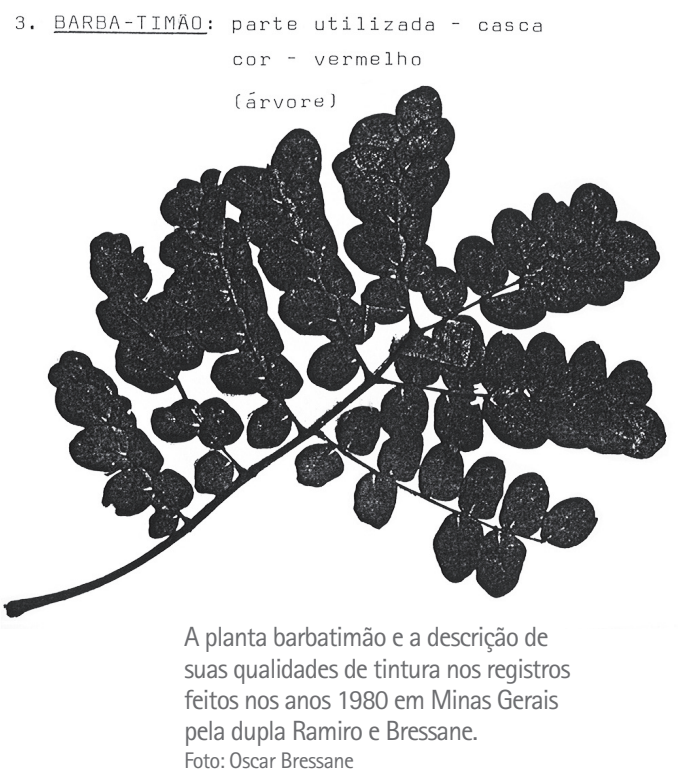

Quem se lembra da beleza dos bordados sobre panos de lã, os fardos, vindos das urnas funerárias da civilização peruana de Paracas, expostas ano passado no Sesi de São Paulo? Ali, nos mantos dessa coleção de têxteis do Museu Nacional de Arqueologia, Antropologia e História do Peru, contavam-se muitas dezenas de cores orgânicas as quais tingiram os fios que magnificamente os bordaram, fios cujas cores se preservaram sensivelmente inalteradas desde 0 ano 200 a.C. Tecnologia de ponta?

Nos Estados Unidos hoje encontram-se, no varejo e a preços adequados, tintas à base de vegetais e de soja e um conjunto de tecidos planos, de peças de vestuário e de acessórios integralmente confeccionados em algodão orgânico ou bambu. Ali o consumidor encontra também um vinil 100\% biodegradável para comunicação visual ao ar livre usando tintas à base de água. Abuse.

0 designer Eber Lopes Ferreira produz e vende tintas de extração natural para uso em diferentes tecidos. Com pesquisa antiga, uma prática de ensino larga pelo Brasil e uma publicação sobre tinturas naturais, ele abre um novo espaço de oficinas em São Paulo. Atente.

Em 1987, os artistas Mario Ramiro e Oscar Bressane, sobre motocicletas em vez de sobre o lombo de burros, reencenam um trecho do longo caminho que os naturalistas e botânicos alemães Von Spix e Von Martius percorreram no século XIX, fazendo um levantamento da fauna e da flora brasileira. Os dois artistas selecionaram o Estado de Minas Gerais, e a tarefa era anotar a mudança da paisagem levando em consideração as gravuras dos naturalistas. Bressane registrava as plantas, experiência adquirida em suas expedições com Burle Marx, enquanto Ramiro, na sua melhor veia de curiosidade polivalente, levantava as espécies vegetais benfazejas para a tinturaria. Isso é registro e dele pouco se conhece. Sabe-se, contudo, que o que o artista faz Deus não desfaz. Ateste.

${ }^{[1]}$ Nota das editoras: Lamentavelmente, na edição anterior de [picote] intitulada De tempos em tempos o final do texto foi cortado. Pedimos desculpas ao autor e a você, leitor, pela nossa falha. Veja a seguir o último parágrafo na íntegra: "0 segundo artista é Jim Shaw, que nos presenteia com uma coleção de trabalhos cujas imagens eu apresento ao longo desta coluna. Esses trabalhos são de artistas anônimos que o inglês Jim Shaw colecionou em lojas de quinquilharias mundo afora. Trago essas imagens para comentar que enquanto houver nas comunidades artistas anônimos como esses e enquanto nós os pudermos conhecer, ainda que através do esforço de outros artistas, eu diria que o mundo está a salvo."

\section{REFERÊNCIA}

FLETCHER, Kate. Sustainable fashion \& textiles: design journeys. Londres: Earthscan, 2008.

\section{SAIBA MAIS}

Climatex: www.climatex.com

Eber Lopes Ferreira: corantesnaturais@gmail.com

Mario Ramiro: www.autopsi.de

Trigema: www.trigema.de

Victor: www.victor-innovatex.com 